\title{
Synthesis of Surface Organopalladium Intermediates in Coupling Reactions: The Mechanistic Insight
}

Boyapati M. Choudary, ${ }^{*}{ }^{\dagger}$ Sateesh Madhi, ${ }^{\dagger}$ Mannepalli L. Kantam, ${ }^{\dagger}$ Bojja Sreedhar ${ }^{\dagger}$ and Yasuhiro Iwasawa*

Inorganic Chemistry Division, Indian Institute of Chemical Technology, Hyderabad -500 007, and Department of Chemistry, Graduate School of Science, The University of Tokyo, Hongo, Bunkyo-ku, Tokyo 113-0033

\section{Supporting Online Material}

General: ${ }^{1} \mathrm{H}$ NMR spectra were recorded on a Varian Gemini $200 \mathrm{MHz}$ spectrometer. The chemical shifts $(\delta)$ are reported in ppm, using TMS as an internal standard and $\mathrm{CDCl}_{3}$ as solvent. X-ray photoemission spectra were recorded on a KRATOS AXIS 165 with a dual anode (Mg and $\mathrm{Al}$ ) apparatus using the $\mathrm{Mg} \mathrm{K} \alpha$ anode. The pressure in the spectrometer was about $10^{-9}$ Torr. For energy calibration we have used the carbon $1 \mathrm{~s}$ photoelectron line. The carbon 1s binding energy was taken to be $284.6 \mathrm{eV}$. Spectra were deconvoluted using Sun Solaris based Vision 2 curve resolver. The location and the full width at half maximum (FWHM) for a species was first determined using the spectrum of a pure sample. The location and FWHM of products, which were not obtained as pure species, were adjusted until the best fit was obtained. Symmetric Gaussian shapes were used in all cases. Binding energies for identical samples were, in general, reproducible to within $\pm 0.1 \mathrm{eV}$. TGA-MS thermograms were 
recorded on Mettler-Toledo TGA/SDTA $821^{\mathrm{e}}$ instrument coupled to Balzers Thermostar GSD $300 \mathrm{~T}$ in the temperature range $25-1000^{\circ} \mathrm{C}$ with a heating rate of $10^{\circ} \mathrm{C} / \mathrm{min}$ in nitrogen atmosphere.

EXAFS spectra at Pd K-edge were measured in a transmission mode at room temperature at the BL-10B station of the photon Factory in the Institute of Materials Structure Science, High Energy Accelerator Research Organization (KEK-IMSS-PF). The energy and current of electrons in the storage ring were $2.5 \mathrm{GeV}$ and $250-400 \mathrm{~mA}$, respectively. X-rays from the storage ring were monochromatized by a $\mathrm{Si}(311)$ channel cut crystal. Ionization chambers filled with pure $\mathrm{Ar}$ and $\mathrm{Kr}$ gas were used to monitor the incident and transmitted X-rays, respectively. The EXAFS spectra were analyzed with the UWXAFS package. The threshold energy $E_{0}$ was tentatively set at the inflection point of the absorption edge. The background was subtracted by the AUTOBK program. The $k^{3}$-weighted EXAFS data were Fourier transformed into $R$-space. The curve-fitting analysis was carried out using the FEFFIT program in the $R$-space. The $k$-range and $\mathrm{R}$ space were $30-130$ or $30-160 \mathrm{~nm}^{-1}$ and $0.1-0.3 \mathrm{~nm}$, respectively. The number of independent parameters $\left(N_{\text {idp }}\right)$ in the curve-fitting of the Pd catalysts was evaluated to be 14 or 18 from Nyquist's law: $N_{\text {idp }}=2 \Delta k \Delta R \pi^{-1}+2$. The fitting parameters were coordination numbers $(\mathrm{CN})$, interatomic distances $(R)$, Debye-Waller factors $(\sigma)$, and a correction-of-edge energy $\left(\Delta E_{0}\right)$. The same $\Delta E_{0}$ was used for all the shells in a sample. The phase shifts and backscattering amplitudes were calculated by the FEFF8 code. The coefficient of the multiphoton effect $\left(\mathrm{S}_{0}{ }^{2}\right)$ was fixed as 1.0 for the fitting. 
Tetra-n-butyl ammonium bromide, NAIL purchased from CDH was dried and degassed by exposing the melt to vacuum/nitrogen for at least $2 \mathrm{~h}$ prior to use. $\mathrm{MgCl}_{2} \cdot 6 \mathrm{H}_{2} \mathrm{O}$ and $\mathrm{AlCl}_{3} \cdot 6 \mathrm{H}_{2} \mathrm{O}$ were purchased from Aldrich. Styrene, phenylboronic acid, phenylacetylene and tin reagents were purchased from Fluka. 4-chloroanisole was purchased from Merck and used as received. All the other solvents and chemicals were obtained from commercial sources and used as such without further purification. All the reactions were carried out under nitrogen atmosphere.

\section{Preparation of the catalyst:}

LDH (Mg-Al-Cl) preparation was based on literature procedure. ${ }^{1}$ A mixture of $\mathrm{MgCl}_{2} \cdot 6 \mathrm{H}_{2} \mathrm{O}(30.49 \mathrm{~g}, 0.15 \mathrm{mmol})$ and $\mathrm{AlCl}_{3} .6 \mathrm{H}_{2} \mathrm{O}(12.07 \mathrm{~g}, 0.05 \mathrm{mmol})$ was dissolved in $200 \mathrm{~mL}$ of deionised water. To this aqueous solution, $100 \mathrm{~mL}$ of $\mathrm{NaOH}(2 \mathrm{M})$ solution was slowly added at $25{ }^{\circ} \mathrm{C}$ and a further amount of $2 \mathrm{M} \mathrm{NaOH}$ solution was added to maintain a $\mathrm{pH}$ of 10 under nitrogen flow. The resulting suspension was stirred overnight at $70{ }^{\circ} \mathrm{C}$. The solid product was isolated by filtration, washed thoroughly with deionised water and dried overnight at $80{ }^{\circ} \mathrm{C}$. All the synthetic steps were carried out using decarbonated water.

$\mathbf{N a}_{2} \mathbf{P d C l}_{4}: \mathrm{Na}_{2} \mathrm{PdCl}_{4}$ was prepared ${ }^{2}$ by refluxing $\mathrm{PdCl}_{2}(1.77 \mathrm{~g}, 10 \mathrm{mmol})$ and sodium chloride $(0.58 \mathrm{~g}, 10 \mathrm{mmol})$ in $50 \mathrm{~mL}$ for $4 \mathrm{~h}$. The solution was filtered in hot condition to avoid $\mathrm{NaCl}$ contamination. Evaporation of the filtrate gave dark brown flakes $(2.88 \mathrm{~g}, 98 \%)$. 
LDH-PdCl 4 : $\mathrm{Mg}-\mathrm{Al}-\mathrm{Cl}(1.5 \mathrm{~g})$ was suspended in $150 \mathrm{~mL}$ of aqueous $\mathrm{Na}_{2} \mathrm{PdCl}_{4}$ $(0.441 \mathrm{~g}, 1.5 \mathrm{mmol})$ solution and stirred at $25^{\circ} \mathrm{C}$ for $12 \mathrm{~h}$ under nitrogen atmosphere. The solid catalyst was filtered, washed thoroughly with $500 \mathrm{~mL}$ of water and vacuum-dried to obtain $1.752 \mathrm{~g}$ of LDH-PdCl 4 (0.86 mmol of Pd per gram). ${ }^{3}$

LDH-Pd ${ }^{0}:$ LDH-PdCl 4 (1 g) was reduced with hydrazine hydrate $(1 \mathrm{~g}, 20 \mathrm{mmol})$ in ethanol $(10 \mathrm{~mL})$ for $3 \mathrm{~h}$ at room temperature, filtered and washed with ethanol to give an air stable black powder $\left(0.95 \mathrm{mmol}\right.$ of Pd per gram). ${ }^{3}$

\section{Synthesis of Surface Transient Organometallic (STO) intermediates:}

LDH-MeOC ${ }_{6} \mathbf{H}_{4} \mathbf{P d C l}$ (OA1): In a $100 \mathrm{~mL}$ Schlenk flask, the NAIL (3.23 g, 10 mmol) was heated to melt $\left(130{ }^{\circ} \mathrm{C}\right)$ and degassed with nitrogen and vacuum prior to the addition of other reagents. After cooling the NAIL to room temperature, $\mathrm{LDH}^{\mathrm{Pd}}{ }^{0}$ (105 $\mathrm{mg}, 10 \mathrm{~mol} \%)$, 4-chloroanisole $(28.2 \mathrm{mg}, 0.2 \mathrm{mmol})$ were then added and the reaction was heated to $130{ }^{\circ} \mathrm{C}$ and stirred for $40 \mathrm{~h}$ under nitrogen atmosphere. After completion of the reaction, the solution was filtered and washed with water and dichloromethane to obtain surface transient organometallic (STO) intermediate LDH- $\mathrm{MeOC}_{6} \mathrm{H}_{4} \mathrm{PdCl}$ (OA1) in good yield.

LDH-PhPdCl (OA1'): In a $100 \mathrm{~mL}$ Schlenk flask, the NAIL (3.23 g, $10 \mathrm{mmol}$ ) was heated to melt $\left(130^{\circ} \mathrm{C}\right)$ and degassed with nitrogen and vacuum prior to the addition of other reagents. After cooling the NAIL to room temperature, $\mathrm{LDH}^{\mathrm{Pd}} \mathrm{d}^{0}(105 \mathrm{mg}, 10$ mol\%), chlorobenzene ( $23 \mathrm{mg}, 0.2 \mathrm{mmol}$ ) were then added and the reaction was heated to $130{ }^{\circ} \mathrm{C}$ and stirred for $30 \mathrm{~h}$ under nitrogen atmosphere. After completion of the reaction, 
the solution was filtered and washed with water and dichloromethane to obtain STO intermediate LDH-PhPdCl (OA1') in good yield.

Scheme S1. Oxidative Addition of Haloarenes

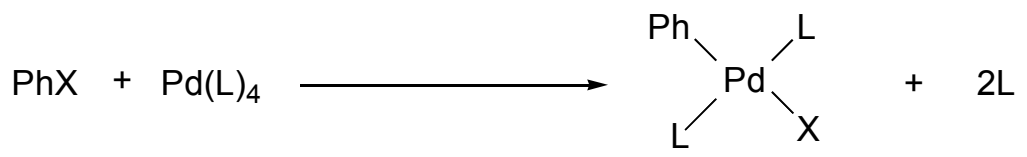

\section{Heck coupling}

HK2 ( $\sigma$-complex): The STO intermediate, $\mathrm{LDH}_{-\mathrm{MeOC}} \mathrm{H}_{4} \mathrm{PdCl}$ (OA1), styrene (52 mg, $0.5 \mathrm{mmol})$, tri- $n$-butylamine (111 mg, $0.6 \mathrm{mmol}$ ), and $N$-methyl pyrrolidinone (5 $\mathrm{mL}$ ) were charged in a round-bottomed flask. Reaction was carried out at $100{ }^{\circ} \mathrm{C}$ for $5 \mathrm{~h}$ under nitrogen atmosphere. After completion of the reaction, the solution was filtered and washed with water and dichloromethane to obtain STO intermediate (HK2) in quantitative yield.

\section{Synthesis of trans-4-methoxystilbene from HK2 intermediate:}

The vacuum dried STO intermediate (HK2, $616 \mathrm{mg}$ ) on heating at $100{ }^{\circ} \mathrm{C}$ in NMP for $5 \mathrm{~h}$ under nitrogen atmosphere gave LDH-Pd ${ }^{0}(592 \mathrm{mg})$ and trans-4-methoxystilbene (20 $\mathrm{mg}$ ) in $88 \%$ isolated yield of the theoretical yield, which is calculated based on weight difference between HK2 and LDH-Pd ${ }^{0}$.

HK2' (б-complex): The STO intermediate, LDH-PhPdCl (OA1'), styrene (52 mg, $0.5 \mathrm{mmol})$, tri- $n$-butylamine $(111 \mathrm{mg}, 0.6 \mathrm{mmol})$, and NMP $(5 \mathrm{~mL})$ were charged in a round-bottomed flask. Reaction was carried out at $100{ }^{\circ} \mathrm{C}$ for $5 \mathrm{~h}$ under nitrogen atmosphere. After completion of the reaction, the solution was filtered and washed with 
water and dichloromethane to obtain STO intermediate (HK2') in quantitative yield.

\section{Synthesis of trans-stilbene from HK2' intermediate:}

The vacuum dried STO intermediate (HK2', $641 \mathrm{mg}$ ), on heating at $100{ }^{\circ} \mathrm{C}$ in NMP for $5 \mathrm{~h}$ under nitrogen atmosphere gave LDH-Pd ${ }^{0}(594 \mathrm{mg})$ and trans-stilbene (36 $\mathrm{mg}$ ) in $92 \%$ isolated yield of the theoretical yield, which is calculated based on weight difference between HK2' and LDH-Pd ${ }^{0}$.

Our objective is to elucidate mechanism for coupling reactions by the isolation and identification of the reactive intermediates unambiguously on the solid support. We opted Stille-type reaction facilitated by KOAc, which is easily detectable by ESCA and TGA-MS and Suzuki cross coupling coaxed by easily discernable KF by ESCA to provide a strong evidence for the exchange of anion of the base with the $\mathrm{Cl}$ of the $\mathrm{ArPdCl}$ complex followed by metalation both in the Suzuki and Stille-type reactions.

\section{Suzuki coupling}

The use of KF in the Suzuki cross coupling reactions is well established. ${ }^{4-8}$ Various bases (organic and inorganic) have been used in our studies in the present coupling reaction. We obtained optimum yields using KF as a base. We have reported the Suzuki cross coupling of deactivated chloroarenes using LDH-Pd ${ }^{0}$ catalyst. The basic LDH surface in conjunction with a KF increases the electron density of the Pd center to promote metalation, which is responsible for higher activity. In view of the above 
and the easier identification of STO intermediates (SZ) by ESCA with KF (F 1s line at $685.3 \mathrm{eV}$ ) base prompted us to undertake studies with KF.

LDH-MeOC $6 \mathrm{H}_{4} \mathrm{PdF}$ (SZ2) with 2 equiv. of potassium fluoride: The STO intermediate $\mathrm{LDH}-\mathrm{MeOC}_{6} \mathrm{H}_{4} \mathrm{PdCl}$ (OA1), potassium fluoride $(23 \mathrm{mg}, 0.4 \mathrm{mmol})$ and acetonitrile $(5 \mathrm{~mL})$ were charged in a round-bottomed flask. Reaction was carried out at $80{ }^{\circ} \mathrm{C}$ for $5 \mathrm{~h}$ under nitrogen atmosphere. After completion of the reaction, the solution was filtered and washed with water and dichloromethane to obtain STO intermediate LDH-MeOC ${ }_{6} \mathrm{H}_{4} \mathrm{PdF}$ (SZ2) in good yield.

LDH-MeOC $6 \mathrm{H}_{4} \mathrm{PdF}$ (SZ2) with 0.5 equiv. of potassium fluoride: The STO intermediate $\mathrm{LDH}-\mathrm{MeOC}_{6} \mathrm{H}_{4} \mathrm{PdCl}$ (OA1), potassium fluoride $(3 \mathrm{mg}, 0.05 \mathrm{mmol}$ ) and acetonitrile $(5 \mathrm{~mL})$ were charged in a round-bottomed flask. Reaction was carried out at $80{ }^{\circ} \mathrm{C}$ for $5 \mathrm{~h}$ under nitrogen atmosphere. After completion of the reaction, the solution was filtered and washed with water and dichloromethane to obtain STO intermediates LDH-MeOC ${ }_{6} \mathrm{H}_{4} \mathrm{PdCl}$ (OA1) and $\mathrm{LDH}-\mathrm{MeOC}_{6} \mathrm{H}_{4} \mathrm{PdF}$ (SZ2).

LDH-PhPdF (SZ2'): The STO intermediate LDH-PhPdCl (OA2), potassium fluoride $(23 \mathrm{mg}, 0.4 \mathrm{mmol})$ and acetonitrile $(5 \mathrm{~mL})$ were charged in a round-bottomed flask. Reaction was carried out at $80{ }^{\circ} \mathrm{C}$ for $5 \mathrm{~h}$ under nitrogen atmosphere. After completion of the reaction, the solution was filtered and washed with water and dichloromethane to obtain STO intermediate, LDH-PhPdF (SZ2') in good yield. 
LDH-MeOC $\mathbf{6}_{6} \mathrm{H}_{4} \mathbf{P h P d B}(\mathbf{O H})_{2}$ (SZ3): The STO intermediate $\mathrm{LDH}-\mathrm{MeOC}_{6} \mathrm{H}_{4} \mathrm{PdF}$ (SZ2), phenylboronic acid (25 mg, $0.2 \mathrm{mmol})$ and 1,4-dioxane/water $(5: 1,5 \mathrm{~mL})$ were charged in a round-bottomed flask. Reaction was carried out at $100{ }^{\circ} \mathrm{C}$ for $10 \mathrm{~h}$ under nitrogen atmosphere. After completion of the reaction, the solution was filtered and washed with water and dichloromethane to obtain STO intermediate LDH$\mathrm{MeOC}_{6} \mathrm{H}_{4} \mathrm{PhPdB}(\mathrm{OH})_{2}$ (SZ3) in good yield.

\section{Synthesis of 4-methoxybiphenyl from SZ3 intermediate:}

The vacuum dried STO intermediate $(\mathrm{SZ3}, 611 \mathrm{mg})$ on heating at $100{ }^{\circ} \mathrm{C}$ at in 1,4-dioxane/water $(5: 1,5 \mathrm{~mL})$ for $5 \mathrm{~h}$ under nitrogen atmosphere gave LDH-Pd ${ }^{0}(597 \mathrm{mg})$ and 4-methoxybiphenyl $(13 \mathrm{mg})$ in $94 \%$ isolated yield of the theoretical yield, which is calculated based on weight difference between SZ3 and LDH-Pd ${ }^{0}$.

LDH-PhPhPdB(OH) ${ }_{2}$ (SZ3'): The STO intermediate LDH-PhPdF (SZ2), phenylboronic acid (25 mg, $0.2 \mathrm{mmol})$ and 1,4-dioxane/water $(5: 1,5 \mathrm{~mL})$ were charged in a round-bottomed flask. Reaction was carried out at $100{ }^{\circ} \mathrm{C}$ for $10 \mathrm{~h}$ under nitrogen atmosphere. After completion of the reaction, the solution was filtered and washed with water and dichloromethane to obtain STO intermediate $\mathrm{LDH}-\mathrm{PhPhPdB}(\mathrm{OH})_{2}\left(\mathbf{S Z 3}^{\prime}\right)$ in quantitative yield.

\section{Synthesis of biphenyl from SZ3' intermediate:}

The vacuum dried STO intermediate (SZ3', $617 \mathrm{mg}$ ) on heating at $100{ }^{\circ} \mathrm{C}$ in 1,4dioxane/water $(5: 1,5 \mathrm{~mL})$ for $5 \mathrm{~h}$ under nitrogen atmosphere gave LDH-Pd ${ }^{0}(598 \mathrm{mg})$ 
and biphenyl (18 $\mathrm{mg})$ in $90 \%$ isolated yield of the theoretical yield, which is calculated based on weight difference between SZ3' and LDH-Pd ${ }^{0}$.

\section{Sonogashira coupling}

LDH-PhPdCCPh (SG2): The STO intermediate, LDH-PhPdCl (OA1'), phenylacetylene (51 mg, $0.5 \mathrm{mmol}$ ) and cuprous iodide ( $4 \mathrm{mg}, 0.02 \mathrm{mmol})$, and THFwater $(1: 2,6 \mathrm{~mL})$ were charged in a round-bottomed flask. Reaction was carried out at 80 ${ }^{\circ} \mathrm{C}$ for $12 \mathrm{~h}$ under nitrogen atmosphere. After completion of the reaction, the solution was filtered and washed with water and dichloromethane to obtain STO intermediate LDH$\mathrm{PhPdC} \equiv \mathrm{CPh}$ (SG2) in good yield.

\section{Synthesis of diphenylacetylene from SG2 intermediate:}

The vacuum dried STO intermediate (SG2, $610 \mathrm{mg}$ ) on heating at $80{ }^{\circ} \mathrm{C}$ at in THF/water $(1: 2,6 \mathrm{~mL})$ for $5 \mathrm{~h}$ under nitrogen atmosphere gave LDH-Pd ${ }^{0}(596 \mathrm{mg})$ and diphenylacetylene $(13 \mathrm{mg})$ in $95 \%$ isolated yield of the theoretical yield, which is calculated based on weight difference between SG2 and LDH-Pd ${ }^{0}$.

\section{Stille-type coupling}

The reductive elimination products of the Suzuki and Stille ${ }^{12,13}$ cross coupling reaction are the same (Ar-Ar'), while Suzuki and Stille-type ${ }^{3,13,14}$ cross coupling reactions yield different products (Ar-Ar' and $\mathrm{Ar}-\mathrm{SnR}_{3}$ ). In view of this it was felt to opt for Stilletype reaction. Since our interest is to isolate and study the transient organometallic intermediates primarily by XPS, Sn (stannane), which gives easily discernable lines at $485.7 \mathrm{eV}$ and $494.1 \mathrm{eV}$ for its $3 \mathrm{~d}_{5 / 2}$ and $3 \mathrm{~d}_{3 / 2}$, respectively, is the best option. The base drives to yield Stille-type product $\mathrm{ArSnR}_{3}$ via the exchange of anion of the base with the 
chloride of the $\mathrm{ArPdCl}$ to give $\mathrm{ArPdOAc}$ and followed by metalation, $\mathrm{ArPdSnR}_{3}{ }^{14}$ Stilletype product has wide synthetic applications. ${ }^{15-21}$

LDH-PhPdOAc (ST2): The STO intermediate LDH-PhPdCl (OA1'), potassium acetate $(40 \mathrm{mg}, 0.4 \mathrm{mmol})$ and NMP $(4 \mathrm{~mL})$ were charged in a round-bottomed flask. Reaction was carried out at $50{ }^{\circ} \mathrm{C}$ for $5 \mathrm{~h}$ under nitrogen atmosphere. After completion of the reaction, the solution was filtered and washed with water and dichloromethane to obtain STO intermediate LDH-PhPdOAc (ST2) in quantitative yields.

LDH-PhPdSnBu 3 (ST3): The STO intermediate LDH-PhPdOAc (ST2), tributyltin hydride $(58 \mathrm{mg}, 0.2 \mathrm{mmol})$ and NMP $(5 \mathrm{~mL})$ were charged in a roundbottomed flask. Reaction was carried out at $50{ }^{\circ} \mathrm{C}$ for $10 \mathrm{~h}$ under nitrogen atmosphere. After completion of the reaction, the solution was filtered and washed with water and dichloromethane to obtain $\mathrm{STO}$ intermediate $\mathrm{LDH}-\mathrm{PhPdSnBu}_{3}$ (ST3) in quantitative yield.

\section{Synthesis of tributylarylstannane from ST3 intermediate:}

The vacuum dried STO intermediate (ST3, $640 \mathrm{mg}$ ) on heating at $50{ }^{\circ} \mathrm{C}$ in NMP for $5 \mathrm{~h}$ under nitrogen atmosphere gave LDH-Pd ${ }^{0}(599 \mathrm{mg})$ and tributylarylstannane (35 $\mathrm{mg}$ ) in $85 \%$ isolated yield of the theoretical yield, which is calculated based on weight difference between ST3 and LDH-Pd ${ }^{0}$.

The final coupling products obtained in all the reactions are subjected for NMR, GC and mass spectroscopy, and the spectra are in accordance with those reported in the literature. 


\section{References}

1. Miyata, S. Clays Clay Miner. 23, 369 (1975).

2. Encyclopedia of Reagents for Organic Synthesis; John Wiley \& Sons: Chichester, U. K., 1992; Vol. 4, p 2301.

3. Choudary, B. M.; Madhi, S.; Chowdari, N. S.; Kantam, M. L.; Sreedhar, B. J. Am. Chem. Soc. 2002; 124, 14127.

4. Wolfe J. P.; Buchwald, S. L. Angew. Chem. Int. Ed. 1999, 38, 2413.

5. Wolfe, J. P.; Stinger, R. A.; Yang, B. H.; Buchwald, S. L. J. Am. Chem. Soc. 1999, $121,9550$.

6. Kabalka, G. W.; Wang, L.; Pagni, R. M.; Hair, C. M.; Namboodiri. V. Synthesis 2003, 2, 217.

7. Basu, B.; Das, P.; Bhuiyan, Md. M. H.; Jha, S. Tetahedron Lett. 2003, 44, 3817.

8. Wright, S. W.; Hageman, D. L.; McClure. L. D. J. Org. Chem. 1994, 59, 6095.

9. Miyaura, N.; Yamada, K.; Suginome H.; Suzuki, A. J. Am. Chem. Soc., 1985, 107, 972.

10. Miyaura N.; Suzuki. A. Chem. Rev. 1995, 95, 24571.

11. Zhang, H.; Kwong, F. Y.; Tian, Y.; Chan. K. S. J. Org. Chem., 1998, 63, 6886.

12. Mitchell T. N. Synthesis 1991, 803.

13. Stille, J. K. Angew. Chem., Int. Ed. Engl. 1986, 25, 508.

14. Murata, M.; Watanabe, S.; Masuda, Y. Synlett 2000, 1043.

15. Corsico, E. F.; Postigo, A.; Rossi, R. A. Molecules 2000, 5, 1068. 
16. Yoon, C. H.; Chong, B, D.; Dueno, E.; Jung, K. W. ACS $221^{\text {st }}$ national meeting in San Diego, CA, April, 2001.

17. Hunter, D. H.; Zhu, X. Journal of labelled compounds and radiopharmaceuticals 1999, 42, 653 .

18. Katisifis, A. G.; McPhee, M. E.; Mattner, F.; Ridley, D. D. Australian Journal of Chemistry 1999, 52, 1061.

19. Neumann, W. P. The Organic Chemistry of Tin, Wiley-Interscience, New York 1970.

20. Gielen, M.; de Poorter, B. Rev. Silicon Germanium Tin Lead Compd. 1977, 3, 9.

21. Gielen, M. Rev. Silicon Germanium Tin Lead Compd. 1981, 5, 6. 
Table S-1. Measured binding energies (XPS) and m/z values (TGA-MS) for STO intermediates formed in the coupling reactions.

\begin{tabular}{|c|c|c|c|}
\hline & $\begin{array}{l}\text { Transient } \\
\text { species }\end{array}$ & Binding Energy $(\mathrm{eV})$ & Mass fragments (a.m.u) \\
\hline \multirow[t]{2}{*}{$\begin{array}{l}\text { Oxidative } \\
\text { addition }\end{array}$} & OA1 & $\begin{array}{l}\text { Cl 2p 197.6; 198.4; 199.6; } \\
\text { C 1s 288.8; 292.4; } \\
\text { Pd 3d 337.1; 342. } 3\end{array}$ & $\begin{array}{c}15(\mathrm{Me}) ; 31(\mathrm{OMe}) \\
76\left(\mathrm{C}_{6} \mathrm{H}_{4}\right) \\
107\left(\mathrm{MeOC}_{6} \mathrm{H}_{4}\right)\end{array}$ \\
\hline & OA1' & $\begin{array}{c}\text { Cl 2p 197.6; 198.4; 199.6; } \\
\text { C 1s 288.8; Pd 3d 337.1;342.3 }\end{array}$ & $51\left(\mathrm{C}_{4} \mathrm{H}_{3}\right) ; 77\left(\mathrm{C}_{6} \mathrm{H}_{5}\right)$ \\
\hline \multirow[t]{2}{*}{ Heck } & HK2 & $\begin{array}{c}\mathrm{Cl} 2 \mathrm{p} 197.6 ; 198.4 ; 199.6 \\
\mathrm{C} 1 \mathrm{~s} 284.2 ; 285.3 \\
288.8 ; 292.0 \\
\text { Pd 3d } 336.4 ; 342.2^{\mathrm{a}}\end{array}$ & $\begin{array}{c}15(\mathrm{Me}) ; 30(\mathrm{Cl}) \\
36\left(\mathrm{CH}_{2} \mathrm{O}\right) ; 51\left(\mathrm{C}_{4} \mathrm{H}_{3}\right) \\
90\left(\mathrm{C}_{7} \mathrm{H}_{6}\right) ; 91\left(\mathrm{C}_{7} \mathrm{H}_{7}\right) \\
103\left(\mathrm{C}_{8} \mathrm{H}_{7}\right) ; 104\left(\mathrm{C}_{8} \mathrm{H}_{8}\right) \\
107\left(\mathrm{MeOC}_{6} \mathrm{H}_{4}\right)\end{array}$ \\
\hline & HK2' & $\begin{array}{c}\text { Cl 2p 197.6; } 198.4 ; 199.6 \\
\text { C 1s 285.3; 287.1; } 289.0 \\
\operatorname{Pd} 3 d 336.3 ; 342.4\end{array}$ & $\begin{array}{c}51\left(\mathrm{C}_{4} \mathrm{H}_{3}\right) ; 77\left(\mathrm{C}_{6} \mathrm{H}_{5}\right) \\
91\left(\mathrm{C}_{7} \mathrm{H}_{7}\right) ; 104\left(\mathrm{C}_{8} \mathrm{H}_{8}\right)\end{array}$ \\
\hline \multirow{3}{*}{ Suzuki } & SZ2 & $\begin{array}{l}\mathrm{Pd} 3 \mathrm{~d} 339.0 ; 345.6 ; \mathrm{F} 1 \mathrm{~s} 685.3 \\
\mathrm{C} 1 \mathrm{~s} \quad 283.9 ; 285.5 ; 287.6\end{array}$ & $\begin{array}{r}19(\mathrm{~F}) ; 51\left(\mathrm{C}_{4} \mathrm{H}_{3}\right) \\
77\left(\mathrm{C}_{6} \mathrm{H}_{5}\right)\end{array}$ \\
\hline & SZ3 & $\begin{array}{c}\text { B 1s 192.6; O 1s 531.7; 532.6 } \\
\text { C 1s 284.4; 285.5; 286.5; } 287.3 ; \\
292.3 \\
\text { Pd 3d 337.5; } 342.3 \\
\end{array}$ & $\begin{array}{c}15(\mathrm{Me}) ; 17(\mathrm{OH}) 19(\mathrm{~F}) ; \\
26\left(\mathrm{C}_{2} \mathrm{H}_{2}\right) 31(\mathrm{OMe}) ; 45 \\
\mathrm{~B}(\mathrm{OH})_{2} 51\left(\mathrm{C}_{4} \mathrm{H}_{3}\right)\end{array}$ \\
\hline & $\mathbf{S Z 3}^{\prime}$ & $\begin{array}{c}\text { B 1s 192.6; O 1s 532.6 } \\
\text { C 1s 283.8; 285.2; } 287.2 \\
\text { Pd 3d 337.5; } 342.3\end{array}$ & $\begin{array}{l}4 \mathrm{~B}(\mathrm{OH})_{2} \\
51\left(\mathrm{C}_{4} \mathrm{H}_{3}\right) \\
77\left(\mathrm{C}_{6} \mathrm{H}_{5}\right)\end{array}$ \\
\hline Sonogashira & SG2 & $\begin{array}{l}\text { C 1s 284.4; 285.3; 286.5 288.1; } \\
\text { 289.1;Pd 3d 337.5; } 341.8\end{array}$ & $51\left(\mathrm{C}_{4} \mathrm{H}_{3}\right) ; 77\left(\mathrm{C}_{6} \mathrm{H}_{5}\right)$ \\
\hline \multirow[b]{2}{*}{ Stille-type } & ST2 & $\begin{array}{c}\text { O 1s } 531.1 ; 532.0 \\
\text { C 1s 284.2;285.0; } 288.9 \\
\text { Pd 3d 337.2; } 341.3\end{array}$ & $43(\mathrm{OAc}) ; 44\left(\mathrm{CO}_{2}\right)$ \\
\hline & ST3 & $\begin{array}{l}\text { Sn 3d 485.7; 494.1; } \\
\text { C 1s } 284.2 ; 285.0 ; 286.3 ; 288.7 \\
\text { Pd 3d } 336.9 ; 339.4\end{array}$ & $\begin{array}{c}15(\mathrm{Me}) ; 26\left(\mathrm{C}_{2} \mathrm{H}_{2}\right) \\
29\left(\mathrm{C}_{2} \mathrm{H}_{5}\right) ; 43\left(\mathrm{C}_{3} \mathrm{H}_{7}\right) \\
51\left(\mathrm{C}_{4} \mathrm{H}_{3}\right) ; 54\left(\mathrm{C}_{4} \mathrm{H}_{6}\right) \\
56\left(\mathrm{C}_{4} \mathrm{H}_{8}\right) ; 57\left(\mathrm{C}_{4} \mathrm{H}_{9}\right) \\
\quad 77\left(\mathrm{C}_{6} \mathrm{H}_{5}\right)\end{array}$ \\
\hline
\end{tabular}

${ }^{\text {a }}$ The narrow scans of XPS spectra of Pd $3 \mathrm{~d}$ shows $335.0 \mathrm{eV}\left(3 \mathrm{~d}_{5 / 2}\right), 340.2 \mathrm{eV}\left(3 \mathrm{~d}_{3 / 2}\right)$ lines in all the STO intermediates which are not presented here for clarity sake. 

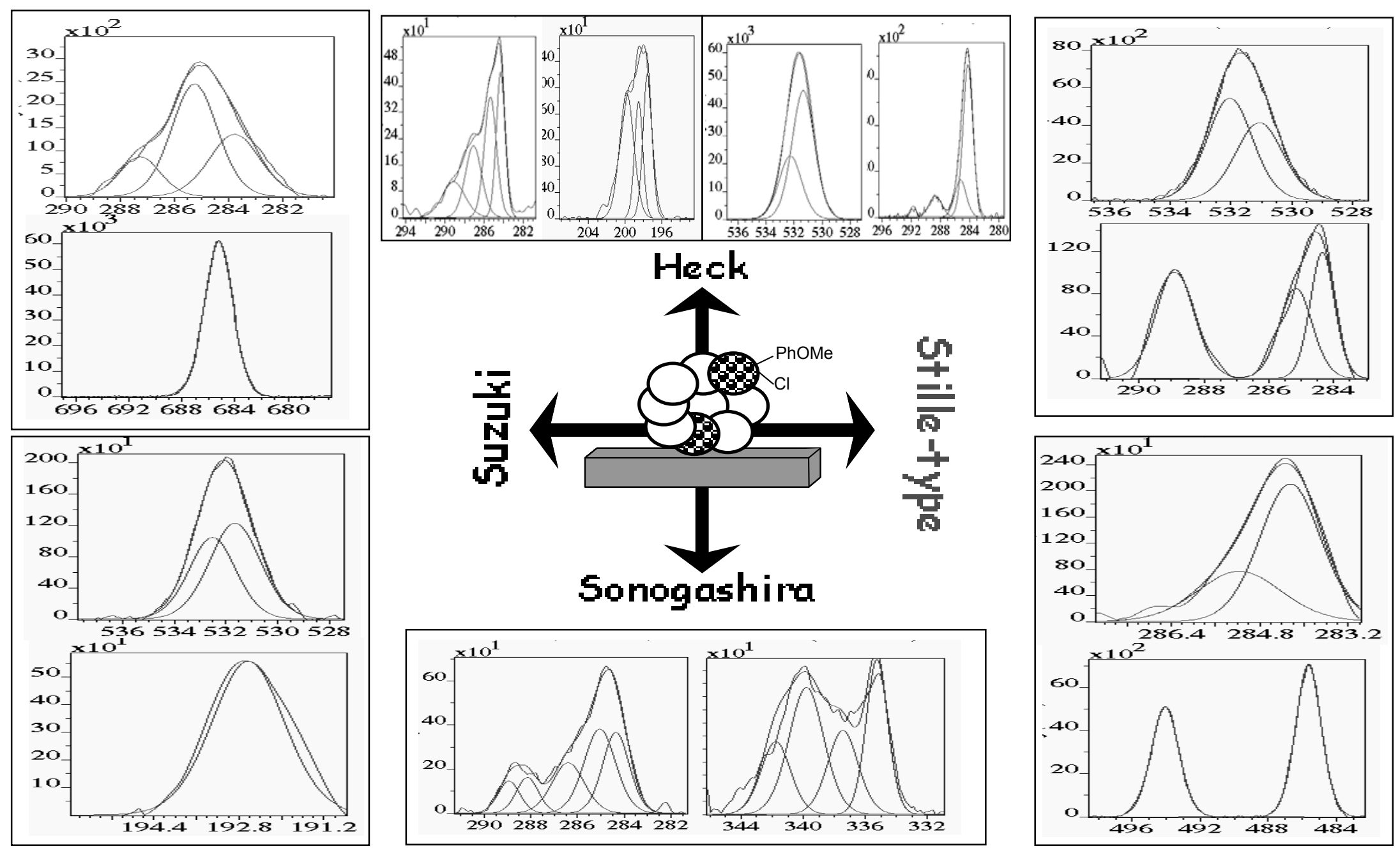

Figure S1. Deconvoluted XPS spectral lines for the STO intermediates formed in the coupling reactions. 


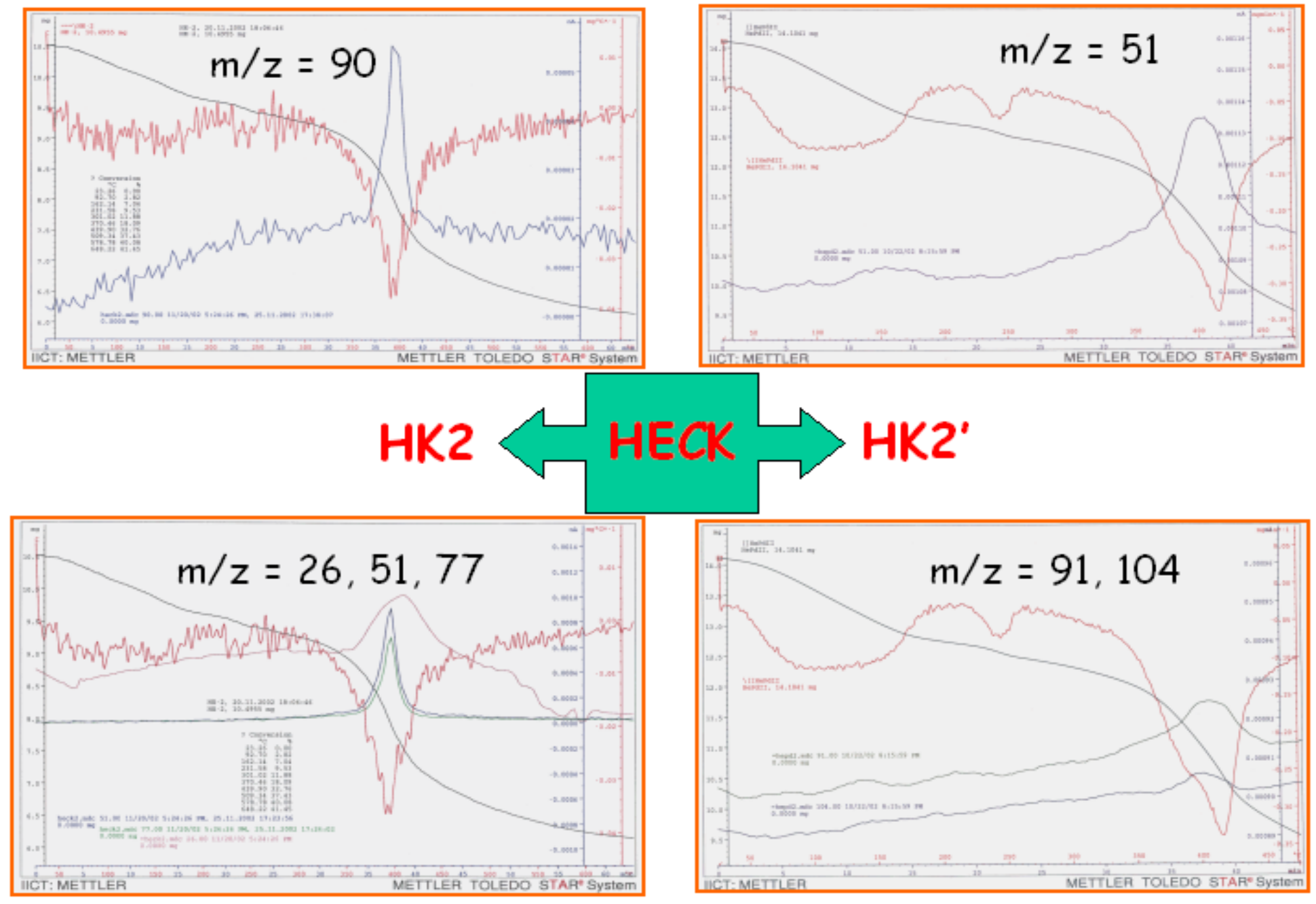

Figure S2. TGA-MS fragments for STO intermediates formed in the Heck coupling reaction. 


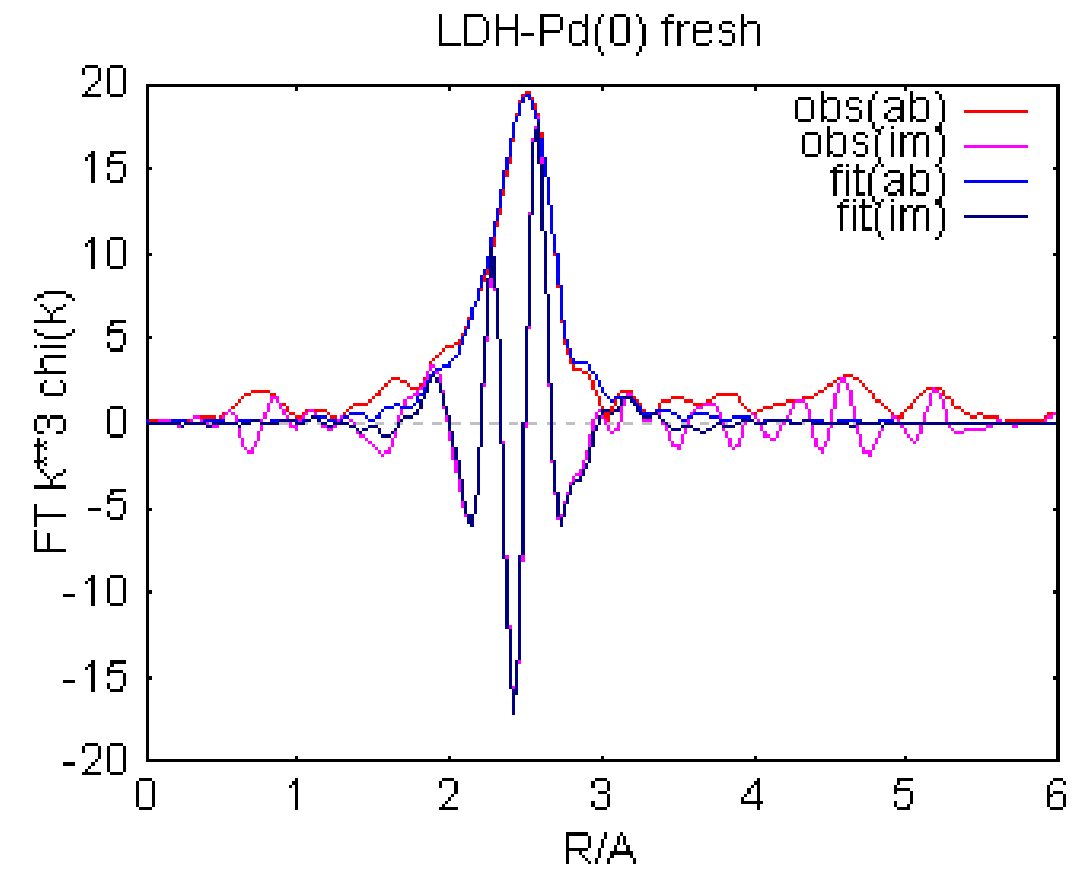

Sample:LDH-Pd(O) Fresh

Bonding: $\mathrm{Pd}-\mathrm{Pd}$

Coordination Number:7.6(5)

Interatomic Distance $(A): 2.739(3)$

Debye-Waller factor $\left(10^{-3} \mathrm{~A}^{2}\right) \cdot 7.0(3)$

Delta E_0 (eV):7.4(7)

Residual factor $(\%): 1.0$

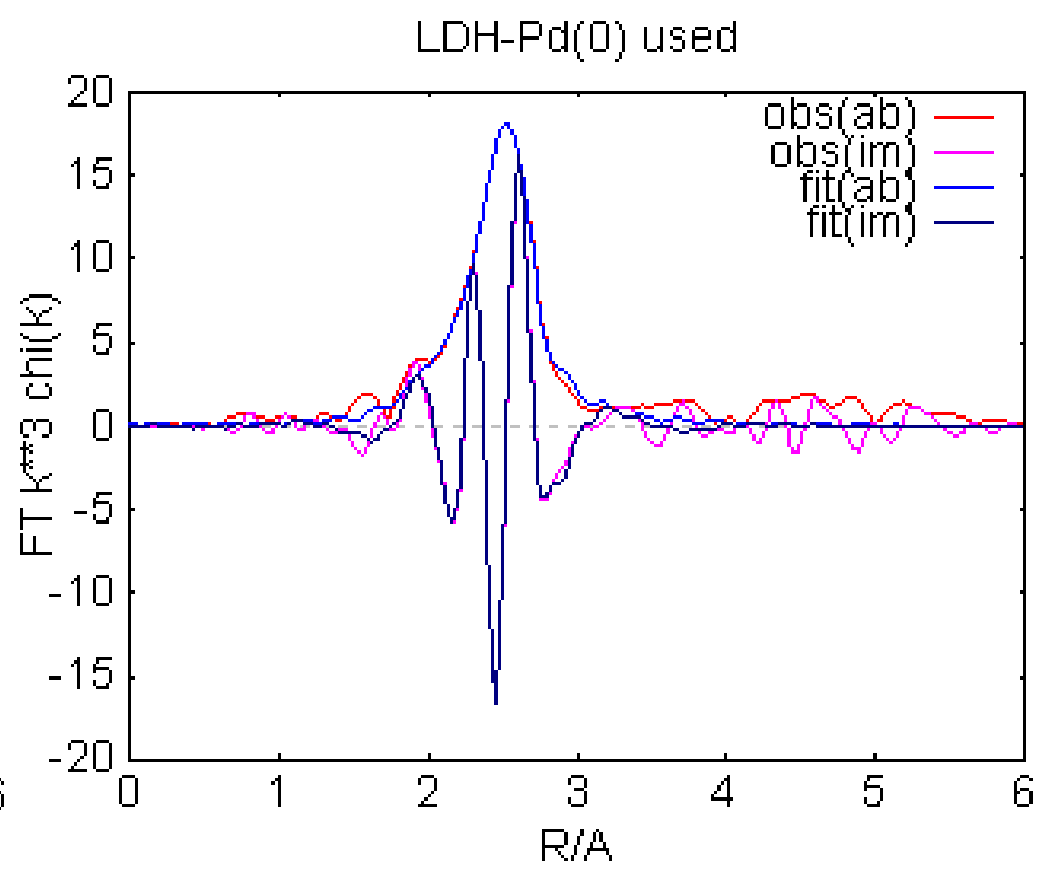

Sample:LDH-Pd(O) Used

Bonding:Pd--Pd

Coordination Number: $8.7(5)$

Interatomic Distance $(\mathcal{A}): 2.765(2)$

Debye-Waller factor $\left(10^{-3} A^{2}\right): 7.8(3)$

Delta E_0 (eV): $5.2(6)$

Residual factor (\%):0.8

Figure S3. EXAFS analysis of the Pd K-edge of fresh and used LDH-Pd(O) catalyst 

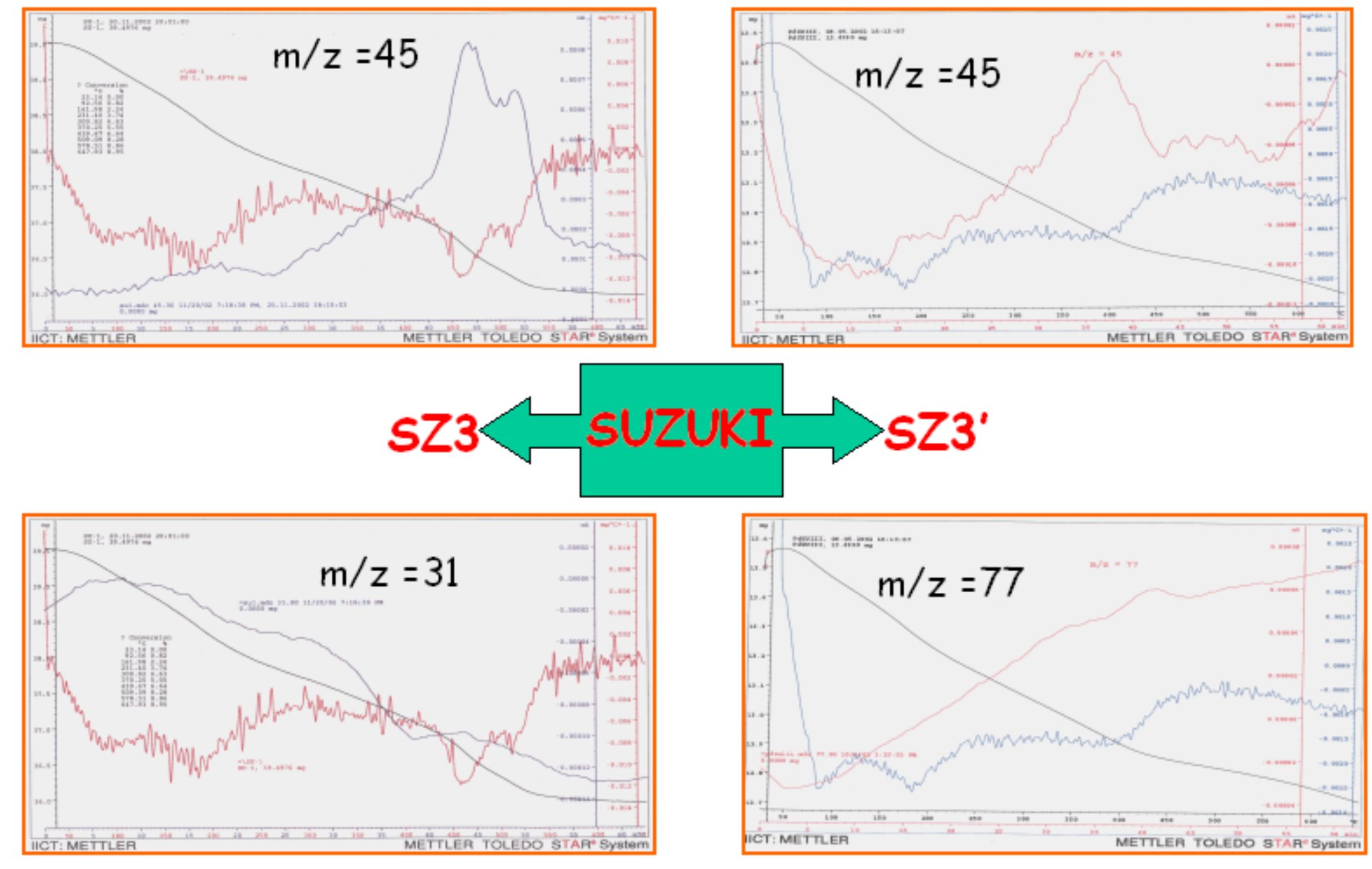

Figure S4. TGA-MS fragments for STO intermediates formed in the Suzuki coupling reaction. S17 


\section{SONOGASHIRA}

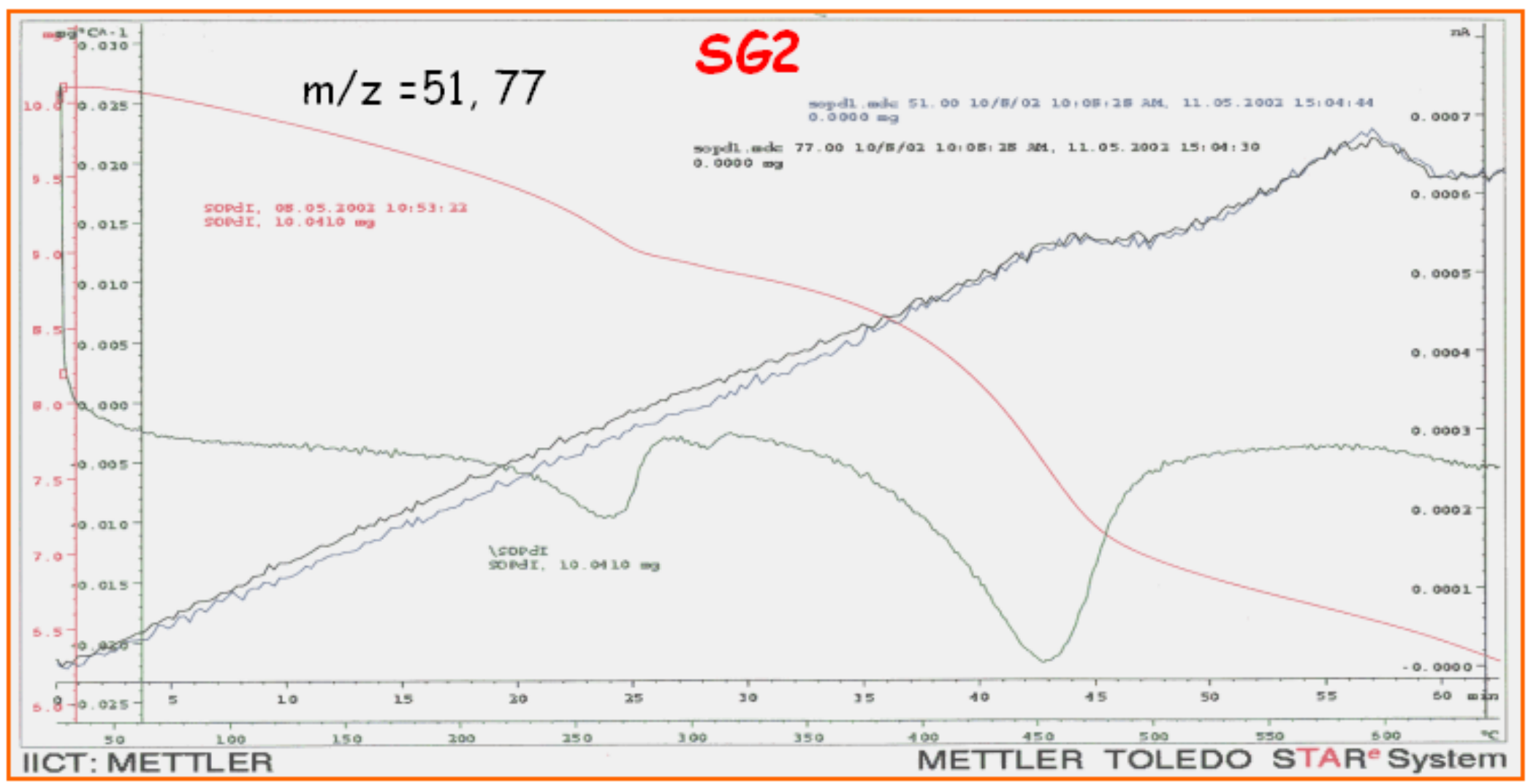

Figure S5. TGA-MS fragments for STO intermediates formed in the Sonogashira coupling reaction. 

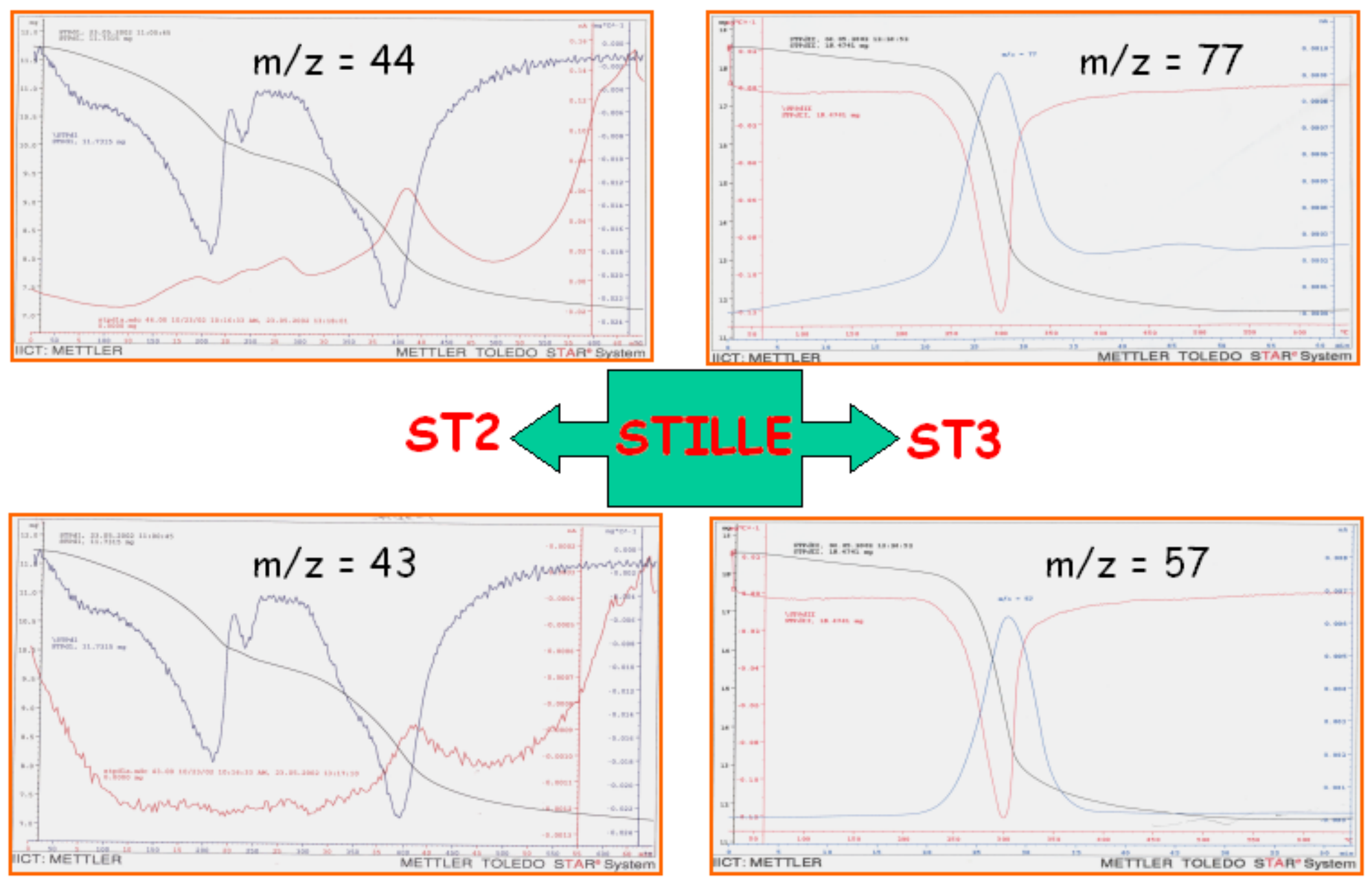

Figure S6. TGA-MS fragments for STO intermediates formed in the Stille-type coupling reaction. 